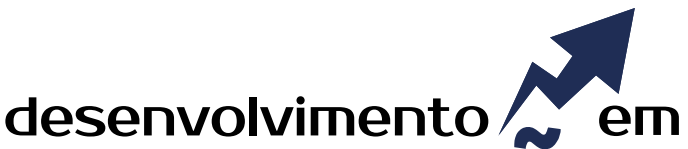 QUESTÃO
}

\section{Processo Decisório nos Conselhos Gestores de Políticas Públicas em Saúde de Minas Gerais}

\author{
http://dx.doi.org/10.21527/2237-6453.2020.52.101-123
}

Recebido em: $14 / 5 / 2019$

Aceito em 2/3/2020

\section{Edson Arlindo Silva, ${ }^{1}$ Claudia Souza Passador, ${ }^{2}$ Bruno de Jesus Lopes, ${ }^{3}$ João Paulo Silva ${ }^{4}$}

\begin{abstract}
RESUMO
O estudo teve como objetivo central analisar o processo decisório dos Conselhos Regionais de Saúde sob a ótica dos princípios de participação e deliberação por intermédio de abordagem qualitativa, com base em estudos de casos múltiplos de caráter interpretativo. Foi realizada pesquisa em profundidade com perspectiva de servir como estudo preliminar para outros trabaIhos mais diversificados. Esta pesquisa em profundidade ocorreu em duas etapas: realizou-se entrevistas com conselheiros(as) representantes titulares e suplentes dos conselhos municipais/regionais estudados, participou-se de reuniões e fóruns organizados pelos conselhos, com o uso da técnica de pesquisa Observação Não Participante, permitindo maior proximidade e detalhamento na obtenção de informações/dados. Os resultados apontaram que há preocupações primordiais nos Conselhos de Saúde em exercer o papel fiscalizador e de melhoria da saúde local e regional, embora existam limites reconhecidos de atuação por parte $\operatorname{dos}(a s)$ conselheiros(as) e críticas a respeito da atuação incipiente em alguns casos. A experiência vivenciada por parte dos(as) conselheiros(as), particularmente pela atuação como lideranças comunitárias e afiliados a partidos políticos/ sindicatos, também é fator relevante para influenciar nas tomadas de decisão sobre ações e políticas públicas direcionadas à saúde. Constatou-se que as redes sociais obtiveram papel de destaque para o estreitamento da comunicação entre Conselhos de Saúde e a comunidade atingida por suas ações. Conclusivamente, o estudo revela o interesse da população pelos serviços ligados aos Conselhos de Saúde, ações de engajamento participativo, transmissão de competência aos conselheiros(as), estreitamento da gestão pública compartilhada mediante novas políticas de cooperação, criação de conselhos itinerantes, investimento em infraestrutura e melhorias na qualidade de prestação de contas e fiscalização dos conselhos.
\end{abstract}

Palavras-chave: Processo decisório. Conselhos de saúde. Administração pública. Regionalidade.

\section{DECISION PROCESS IN THE MANAGING BOARD OF HEALTH PUBLIC POLICIES IN STATE OF MINAS GERAIS}

\begin{abstract}
The study had as its central objective analyzed the decision process of the Regional Health managing Board under the vision of the deliberation and participation principles through a qualitative approach, based on multiple case studies of interpretative character. A deep research was performed with the view to serve as a preliminary study for further more diversified studies. This depth-research was performed in two steps: Interviews were made with council sitting members and alternates of the municipal/regional councils; Participation in meetings and forums organized by the counsels, with the Non Participant Observation Technique, enabling this way a higher proximity and accuracy in obtainment of data and information. The results pointed that there are primordial worries in the health councils to exert the watching role and the improvement of the local and regional health, although there are recognized limits of actuation from councils and critics towards the incipient actuation in some cases. The experience lived form part of the counselors, especially by the performance of some community leaderships and affiliates of unions and political parties, is also a relevant factor to affect the decision making about actions and public policies targeted towards public health. It was found that the social Medias had prominent role to the narrowing of communication between the health councils and the community reached by their actions. Conclusively the study reveals the interest of the population for the services linked to the health counselors, participative actions of engagement, transmission of competency to the counselors, tightening of the shared public management through new cooperation policies, creation of itinerant councils, investment in infra-structure and improvement in the accountability and supervision of the councils.
\end{abstract}

Keywords: Decision process. Health councils. Public administration. Regionality.

\footnotetext{
${ }^{1}$ Pós-Doutor em Administração pela USP. Doutor em Administração pela Universidade Federal de Lavras (Ufla). Professor da Universidade Federal de Uberlândia - Campus Pontal do Triângulo Mineiro. http://lattes.cnpq.br/2119731279726612. https://orcid.org/0000-00018965-100X.edsonasilva@ufu.br

${ }^{2}$ Doutora em Educação pela Universidade de São Paulo (USP). Professora da Universidade de São Paulo (USP). http://lattes.cnpq. br/9233921283764542.https://orcid.org/0000-0002-9333-563X.cpassador@usp.br

${ }^{3}$ Doutor em Extensão Rural pelo Departamento de Economia Rural da Universidade Federal de Viçosa. Professor da Faculdade Dinâmica do Vale do Piranga (Fadip). http://lattes.cnpq.br/3263202273425513. http://orcid.org/0000-0001-9379-1945. bruno.adm2008@yahoo.com.br

${ }^{4}$ Graduado em Administração pela Universidade Federal de Uberlândia (UFU). Bolsista do Pibic/CNPq. Servidor público municipal da prefeitura de Ituiutaba-MG.
} 
Sabe-se que conhecer o funcionamento do sistema de saúde brasileiro, conhecimentos básicos e estruturais, principalmente no que diz respeito ao planejamento estratégico e seus resultados, contribui para compreender as fragilidades e as mudanças desse sistema ao longo do tempo, bem como suas perspectivas futuras, conforme acreditam Fenili, Correa e Barbosa (2017). Antes de o sistema nacional de saúde ser consolidado no Brasil, a sociedade civil brasileira viveu momentos significativos na luta contra o regime de governo ditatorial (1964-1985), em busca de uma ordem político-democrática, tendo como principal conquista a Constituição Federal de 1988, na qual foram garantidos muitos direitos e introduzidas inúmeras transformações na estrutura político-administrativa do Brasil.

Diante desse novo cenário que emergia, os municípios passaram a assumir uma maior autonomia e responsabilidade na provisão de bens e serviços públicos. Por serem os menores entes federativos, há uma maior aproximação com a realidade local; assim, quando atuam de forma efetiva os municípios podem contribuir na formulação de políticas públicas que melhor atendam aos interesses específicos de sua população. Segundo Souza (1997), esse fato se justifica tendo em vista que o ente municipal é único, dada a complexa combinação de fatores sociais, demográficos, políticos e econômicos a ele inerentes.

Partindo do pressuposto de que em um Estado descentralizado é fundamental a presença de canais efetivos de participação, a Constituição Federal de 1988 regulamentou no país a participação social e/ou popular como processo político. Foram criados vários mecanismos de controle, fiscalização e transparência com o objetivo de propiciar à sociedade civil acesso ao governo e participação nas tomadas de decisão sobre diferentes problemas públicos. O surgimento de novos canais de comunicação entre a sociedade civil e o Estado passou a constituir um instrumento fundamental da gestão pública, evidenciando aspectos da dinâmica política democrática (SILVA et al., 2014).

É nesse contexto que surgem os Conselhos Gestores de Políticas Públicas. Os Conselhos foram legitimados no Brasil no momento de aprovação da Constituição Federal de 1988, juntamente com outros mecanismos de participação social, possibilitando significativas mudanças na governança pública com potencialidades para viabilizar a democracia de maneira representativa, direta e dialógica (deliberativa). Os Conselhos Gestores pesquisados e expostos neste artigo possuem caráter paritário e são compreendidos por Deluchey (2012) como aqueles que possuem representantes da sociedade civil e do Estado brasileiro, legitimando-se por ações em torno de políticas públicas e processos de decisão que abrangem toda a população, como é o caso da área da saúde. Nessa direção Deluchey (2012) constatou que a "criação de Conselhos Paritários representaria a consolidação de novas institucionalidades referentes ao modelo liberal de democracia deliberativa, na qual a representação dos cidadãos não se concentraria mais apenas nos processos eleitorais, nem nas instituições que decorrem desse processo".

Disseminados por todo o país, os Conselhos representam uma das principais experiências de participação social na realidade brasileira e uma promessa para resgatar a política e tomar decisões com responsabilidade, incorporando as opiniões da cidadania e promovendo soluções mais justas. Os pressupostos básicos contidos nas leis que os institucionalizam permitem afirmar que se trata de um espaço de participação social 
em que os afetados pelas políticas governamentais são mobilizados a apontar os seus problemas e contribuir para a busca de soluções, o que está muito associado aos pressupostos teóricos e conceituais do modelo de democracia deliberativa.

Embora esses espaços apresentem um avanço para a democracia, pesquisas apontam (TATAGIBA, 2002; COELHO, 2004; AVRITZER, 2009; SILVA, et al., 2014) para as limitações enfrentadas, como a falta de capacitação dos seus membros, assimetria informacional, interferência arbitrária dos gestores públicos, baixo conhecimento sobre a real funcionalidade dos Conselhos de Saúde e muitas outras restrições que colocam em risco um espaço que representa uma conquista de toda a sociedade brasileira. Diante dessas limitações, surge a questão de pesquisa: Como são tomadas as decisões sobre políticas públicas em saúde no âmbito dos conselhos-polo de saúde em sete macrorregiões de saúde do Estado de Minas Gerais? Considerando a complexidade das decisões tomadas no âmbito dos conselhos de políticas públicas e a importância destas institucionalidades para a gestão pública, este trabalho estabeleceu como objetivo central analisar o processo decisório dos Conselhos Gestores de Políticas Públicas de Saúde sob a ótica dos princípios de participação e deliberação. Especificamente pretendeu-se atingir os seguintes objetivos: a) Analisar os papéis desempenhados pelos(as) conseIheiros(as) nas tomadas decisão sobre políticas públicas em saúde em Minas Gerais; b) Compreender como são executadas as funções delegadas aos conselheiros(as); c) Analisar como são pensadas, organizadas e praticadas as participações dos membros representantes dos Conselhos.

Entre os diferentes tipos de Conselhos, optou-se por trabalhar com os Conselhos Municipais de Saúde das cidades-polo de sete macrorregiões de saúde de Minas Gerais, delimitadas pela Secretaria de Estado de Saúde de Minas Gerais (SES-MG), para melhor planejar políticas públicas e intervenções na área da saúde. A princípio a divisão feita pela SES-MG contempla 13 macrorregiões, mas apenas 7 aceitaram participar da pesquisa diante dos objetivos e interesses de pesquisa previamente apresentados aos 13 Conselhos Regionais Polos de Saúde (Figura 1). A escolha dos Conselhos de Saúde como objeto de análise levou em consideração o fato de serem instituições formalizadas, incorporadas legalmente ao processo de gestão de saúde no Brasil. Além disso, foram escolhidos como casos pelo seu potencial de inserção na sociedade nas decisões públicas mais abrangentes, por representar uma das experiências brasileiras mais consolidadas em termos de instituições participativas e por possuir as características definidas por Fung (2004) para instituições intituladas como "Governança Democrática", o que permite vislumbrar a aproximação da teoria à prática.

Por fim, acredita-se que analisar os papéis e as funções desempenhadas pelos Conselhos diante dos grandes desafios que se moldam na sociedade brasileira faz-se relevante tendo em vista que a nossa sociedade possui um perfil de baixa propensão à participação (AVRITZER, 2009). Logo, a expectativa da pesquisa é a de contribuir com reflexões críticas que possam melhorar a compreensão do que se passa nas macrorregiões já definidas como estratégicas para o governo de Minas, em termos de democratização do acesso à saúde de qualidade, universal e gratuita, e revelar como está organizado e funcionando o Conselho de Saúde do município-polo de cada macrorregião definida pela SES-MG (Figura 1), e qual o impacto das deliberações sobre a gestão da saúde pública nas dimensões local e regional. 


\section{MODELO TEÓRICO}

Nesta seção apresenta-se a fundamentação teórica objetivando a sustentação da questão problema do estudo e o auxílio no tratamento de dados e informações levantados e analisados no decurso das etapas de pesquisa. Tal seção inicia-se com um percurso histórico que se propõe a revelar os avanços e os retrocessos que marcaram a criação e o desenvolvimento dos conselhos gestores de políticas públicas no Brasil. Em seguida são expostas as características marcantes dos Conselhos Municipais de Saúde, com ênfase em seus papéis e funções. Na sequência procura-se discutir os elementos constituintes do processo decisório atrelado ao Conselho Municipal de Saúde, destacando os princípios de participação e deliberação.

\section{Descentralização do Estado e a Criação dos Conselhos Gestores de Políticas Públicas}

Com o fim do período ditatorial (1964-1985) no Brasil observou-se, especialmente ao longo da segunda metade da década de 80, uma tendência em associar democratização com as propostas de descentralização político-administrativas do Estado (ARRETCHE, 1999). Nessa direção, o Estado passou a desempenhar um novo papel, voltado para a satisfação das necessidades básicas e de novas demandas que iam surgindo na sociedade, abandonando o modelo intervencionista e permitindo maior agilidade e eficiência em suas ações. $O$ debate sobre a eficácia da gestão das políticas sociais deu destaque à descentralização e a viu como um instrumento que permitiria tornar o poder mais transparente ao controle público. De acordo com Arretche (1999), a descentralização pode ser entendida como um processo que possibilita a transferência de poder dos níveis centrais para os secundários. No Brasil, esse conceito surgiu como reivindicação dos movimentos sociais para democratização e reforma da estrutura de poder governamental. Como marco formal do processo de democratização, tem-se a Constituição Federal de 1988, que trouxe modificações profundas na arquitetura e no funcionamento do Estado, criando estratégias para viabilizar a participação da sociedade civil no âmbito das políticas públicas e incorporando novos atores no processo de tomadas de decisão.

A Constituição de 1988 trouxe um modelo inovador de articulação institucional, criando uma estrutura político-administrativa baseada na descentralização, que implicou a transferência efetiva de poder decisório para os agentes locais da administração municipal. Com as mudanças proposta pela Constituição Federal, os órgãos regionais passaram a ter, dentro dos limites legais estabelecidos, maior autonomia para formular políticas locais, estabelecer prioridades e planejar o atendimento de demandas. Desta forma, a sociedade civil passou a assumir um papel fundamental nesse processo. Nesse sentido, fez-se necessário uma nova filosofia de gestão que possibilitasse a afirmação destas mudanças, introduzindo valores democráticos e atualizando os mecanismos de gestão e, por intermédio de aspectos éticos, da participação da sociedade e da democratização da informação, criar e sugerir novas alternativas (O'DONNELL, 1994; DAHL, 1989).

Como consequência concreta das mudanças na relação entre Estado e sociedade civil, tem-se a construção de diferentes espaços públicos, tanto daqueles que visam a promover o debate amplo no interior da sociedade civil sobre temas muitas vezes 
excluídos de uma agenda pública, quanto daqueles que se constituem como espaços de ampliação e democratização da gestão estatal. Esses espaços podem assumir diferentes formatos, como consultas públicas, comitês, assembleias, conferências municipais, câmaras setoriais, fóruns, orçamentos participativos e diferentes tipos de conseIhos gestores de políticas públicas (DAGNINO, 2002). Como foco do estudo em questão, acredita-se que os Conselhos são espaços públicos que sinalizam a possibilidade de representação de interesses coletivos e que se diferem, no âmbito político, por apresentar um caráter híbrido, uma vez que são simultaneamente parte do Estado e da sociedade civil. Distinguem-se de movimentos e de manifestações sociais, pois sua estrutura é legalmente definida e institucionalizada e sua razão de ser reside na ação conjunta com o aparato estatal na elaboração e gestão de políticas sociais (CARNEIRO, 2006).

Os Conselhos são instrumentos antigos de participação popular, assim como a própria democracia participativa. Segundo Gohn (2001), eles tiveram origem nos clãs visigodos e alguns se tornaram famosos, tais como a Comuna de Paris, os Conselhos dos Sovietes Russos e os Conselhos Operários de Turim. No Brasil, os Conselhos tiveram origem de fato na década de 80 do século 20, devido às mudanças ocorridas no processo de democratização e de descentralização das políticas públicas, criados como instrumentos para mediar uma nova relação entre o Estado e a sociedade civil. $O$ interesse neste mecanismo de participação institucionalizado pelo Estado, após a Constituição de 1988, justifica-se, sobretudo, pelas esperanças depositadas nestes espaços como uma forma renovada do exercício do poder político (CÔRTES, 2005). Segundo Côrtes (2005, p. 19), a institucionalização dos Conselhos deu-se devido "[...] à capacidade dos atores sociais transferirem práticas e informações do nível social para o nível administrativo." Deste modo, os Conselhos permitem ao cidadão comum que possui muitas vezes somente a própria experiência, a participação na tomada de decisão sobre políticas públicas (COELHO, 2004). Os Conselhos podem assumir formas diferenciadas, podendo ser exclusivamente consultivos e sem participação da sociedade civil ou os chamados conselhos gestores de políticas públicas ou setoriais, que garantem a participação da sociedade civil na cogestão das políticas públicas. Apesar dessa diversidade de natureza e finalidade, todos são definidos como espaços intermediários de debate com atuação livre da sociedade civil e base territorial definida, que possuem geralmente funções consultivas ou deliberativas e de controle social, não suprimindo as instâncias formais de governo (AVRITZER; PEREIRA, 2005).

Comparados às esferas públicas tradicionais, os Conselhos se diferem pelo seu caráter inclusivo, pelo aprofundamento dos debates públicos e pela diminuição dos custos de informação, contribuindo assim para a melhoria da qualidade da opinião pública. $A$ participação por meio dos Conselhos é responsável pela articulação entre a burocracia governamental e os beneficiários das políticas públicas, além de promover a transparência nos debates e visibilidade das ações governamentais. Ademais, os Conselhos exercem uma "função pedagógica", contribuindo para a construção da cidadania, do conhecimento governamental e da reconfiguração dos padrões de convivência democrática, conferindo aos membros um sentimento de pertencimento e identificação recíproca (TATAGIBA, 2002). Tratando-se da composição dos Conselhos, a legislação estabelece o princípio da paridade entre o Estado e a sociedade civil como mecanismo de equilíbrio nas decisões. A representação governamental é feita por agentes públicos titulares de 
cargos de direção na administração direta ou indireta, por responsáveis pelas áreas das políticas sociais e por outros que atuem nas áreas afins, por indicação do chefe do poder Executivo. A sociedade civil é representada por conselheiros escolhidos por seus pares, em fórum próprio, entre as entidades e Organizações Não Governamentais prestadoras de serviço, devendo essa composição ser prevista por lei específica, de acordo com as particularidades de cada contexto (AGUIAR; SILVA; FERREIRA, 2015). As reuniões dos Conselhos devem ser abertas à comunidade, a qual não tem direito a voto. Quanto ao funcionamento, cada Conselho elabora seu regimento interno que, depois de aprovado em plenário, é submetido à apreciação do chefe do poder Executivo, que o aprova por meio de decreto. As decisões do Conselho devem ter a forma de resolução e devem ser publicadas em Diário Oficial.

Logo, a criação e o perfil desse espaço público não têm um modelo próprio a ser seguido e nem se esgotam na existência de registros legais. A expectativa sobre o que um Conselho pode ser, na sua área de abrangência, é uma proposta aberta que se configura a partir das ações políticas empreendidas pelos sujeitos que se agregam nesses espaços (AGUIAR; SILVA; FERREIRA, 2015). Apesar do pouco tempo de sua institucionalização e com os diversos desafios encarados no Brasil, os Conselhos Gestores têm se mostrado cada vez mais importantes por apresentarem grande contribuição para uma maior consolidação de aspectos relevantes da democracia participativa, trazidos pela Constituição de 1988. Dessa forma, a eficiência desses órgãos está diretamente relacionada com a participação popular (GOHN, 2001). Nesta direção é importante lembrar que o Conselho não substitui o Estado e nem retira suas responsabilidades, mas permite que ele se torne mais próximo e conhecedor das necessidades da sociedade, promovendo debates em torno das mazelas sociais e possibilidades de melhorias de vida.

\section{Conselhos Municipais de Saúde}

Desde que a Constituição Federal de 1988 legitimou o direito de participação da sociedade na gestão das políticas públicas, foram criados mais de 28.000 Conselhos Setoriais, os primeiros ocorrendo no setor de saúde. Os Conselhos Municipais de Saúde (CMS) funcionam como órgão de instância colegiada e deliberativa, são de natureza permanente e criados por intermédio de lei municipal, em consonância com as disposições legais contidas nas Leis Federais de número 8.080, de 19 de setembro de 1990, e 8.142, de 28 de dezembro de 1990, e na Resolução número 333, de 4 de novembro de 2003 do Conselho Nacional de Saúde. Têm por finalidade a formulação e o controle da execução da Política Municipal de Saúde, inclusive nos aspectos econômicos e financeiros, nas estratégias e na promoção do processo de controle social em toda sua amplitude, no âmbito dos setores públicos e privados. Por possuir atribuições deliberativas, esse Conselho tem o poder de discutir e decidir sobre os rumos das políticas de saúde executadas pelo governo local (OLIVEIRA; PINHEIRO, 2008).

Esse tipo de Conselho é composto por cidadãos, profissionais da área da saúde, instituições governamentais e prestadores de serviços de saúde. De acordo com as Normas Operacionais Básicas que regulam o Sistema Único de Saúde (SUS), o número de representantes da sociedade civil deve ser igual à soma dos representantes dos prestadores de serviços, dos profissionais da área da saúde e das instituições de governo. Assim, $50 \%$ dos conselheiros são representantes de usuários, $25 \%$ representantes de 
trabalhadores da saúde e $25 \%$ representantes de gestores da saúde. Essa configuração institucional dos Conselhos é responsável por capacitar a participação dos cidadãos na governança desse setor, e sua importância se dá não só por levar projetos do governo à população, mas principalmente por transmitir sugestões da população aos vários níveis de governo. Para Arretche (1999), os Conselhos de Saúde têm como principal objetivo proporcionar a cidadania ativa, que se dá por intermédio da participação popular na gestão e efetivação das políticas públicas de saúde. A participação da comunidade tem tido papel relevante na luta para efetivação do SUS. Essa participação está definida na Lei no 8.142 de 1990, que cria o Conselho de Saúde como instância colegiada do SUS, com seu funcionamento sendo uma das condições para repasse de recursos financeiros. Assim, o SUS foi responsável por introduzir a noção de controle social e participação popular no setor da saúde (COELHO, 2004). Atualmente, existem nos municípios brasileiros mais conselheiros do que vereadores. Esse fato evidencia que essa forma de participação se faz muito mais acessível à sociedade civil do que a tradicional representação parlamentar.

\section{Processo Decisório Deliberativo e Participativo}

Desde os primórdios da história política do Brasil o povo é mantido à margem do sistema político. Isso se deve ao fato de a sociedade cultivar uma tradição patrimonialista na qual prevalecem relações com grupos privilegiados e exclui a maioria das pessoas. Este fato, no entanto, não ocorre sem a resistência e luta de grupos mobilizados da sociedade civil, que buscam a participação política e a inclusão de setores menos favorecidos. Segundo Coelho (2004), a participação que foi conquistada ao longo do tempo por diferentes movimentos sempre trouxe o próprio povo como protagonista das conquistas. No contexto das lutas pela democratização no Brasil e com o nascimento dos movimentos sociais, houve o surgimento de novas formas de participação, que contestavam as relações vigentes e estavam desejosas de influenciar os destinos da política. Com o processo de participação via Constituição Federal de 1988, surgiram novos sujeitos sociais na esfera pública, contestando os modos tradicionais de se fazer política e buscando o direito de ter direitos (OLIVEIRA; PINHEIRO, 2008).

As origens do discurso sobre a participação social são várias. É possível encontrar referências à necessidade do uso de novas ferramentas participativas nos manuais das agências internacionais de cooperação para o desenvolvimento, no âmbito dos programas de reforma do Estado e das políticas de descentralização, mas também na prática de alguns governos locais que afirmam que com a participação dos cidadãos na esfera pública é possível criar estratégias de inovação e até mesmo de radicalização da democracia local (MILANI, 2008; O’DONNELL, 1994 DAHL, 1989). O conceito de participação possui inúmeros significados, quase sempre acompanhados de expressões que indicam o agir do sujeito político nos espaços públicos. É comum mencionar participação política, participação social, participação popular, cada uma ligada a uma linha de pensamento e contextualizada nos universos históricos, sociais e culturais em que os sujeitos se inserem (OLIVEIRA; PINHEIRO, 2008). Para Boot e Seligson (1976 apud BORBA, 2012, p. 6), a participação é "um comportamento que influencia ou tenta influenciar a distribuição dos bens públicos". Já segundo Brady (1999 apud BORBA, 2012, p. 737) participação é "a ação de cidadãos comuns com o objetivo de influenciar alguns resultados políticos". 
De acordo com Pateman (1999), a participação pode ser classificada em "pseudoparticipação", "participação parcial" e "participação plena". Na pseudoparticipação, também conhecida como falsa participação, as decisões tomadas são informadas ao grupo no intuito de persuadir os indivíduos a aceitá-las e no objetivo de criar um sentimento de participação. Na participação parcial, os indivíduos participam das tomadas de decisão e sua opinião pode ou não influenciar, no entanto o poder de decisão fica a cargo de um indivíduo ou de um pequeno grupo. Na participação plena todos os indivíduos participam das discussões e possuem as informações necessárias para as tomadas de decisão. A Constituição do Brasil prevê a participação direta dos cidadãos por intermédio dos institutos de democracia direta ou semidireta, como a eleição, o plebiscito, a iniciativa popular de lei, os conselhos gestores, o orçamento participativo e outros canais institucionais de participação popular. Segundo Dallari (1999), a participação política é um direito fundamental de todos os indivíduos e um dever de todos os cidadãos, no entanto muitas vezes ela não passa de meras formalidades, pois o direito de participar das tomadas de decisão fica restrito às elites.

Em se tratando da participação nos Conselhos, é importante ainda apontar alguns desafios. Um obstáculo considerável para a eficácia dos Conselhos deve-se à falta de capacitação de seus membros, o que dificulta exercer seu poder de forma mais qualificada para a gestão das políticas sociais. Nas palavras de Gohn (2001) é preciso uma melhor qualificação para exercer as funções de conselheiro. Outro fator que limita a força dos Conselhos é a falta de mobilização da sociedade. Para que o Conselho exerça seu papel de forma eficaz é indispensável a participação social de suas bases representativas. Segundo Avritzer (2009), a falta de mobilização da sociedade e de segmentos organizados fragiliza a capacidade de pressão social que garantiria a força, legitimidade e representatividade nas negociações de interesse público. Outro fator limitador deve-se ao clientelismo e ao corporativismo no interior dos Conselhos. O'Donnell (1994) constatou que para assegurar a continuidade, a permanência e o aperfeiçoamento da democracia participativa, é preciso priorizar práticas menos dependentes da iniciativa governamental. Para se alcançar a eficiência e a eficácia dos espaços de gestão participativa é necessário, portanto, romper com a burocracia estatal e disseminar o saber técnico, centralizador de poder no aparato estatal. Diversos autores, entre os quais Oliveira e Pinheiro (2008) e Avritzer (2009) acreditam que os mecanismos participativos são ferramentas fracas para se conseguir a igualdade política, devido às desigualdades que permeiam a estrutura sociopolítica, como as desigualdades no acesso à informação, o potencial de influenciar o governo e a capacidade de organização, o que contribuiu para reforçar o déficit de representação de atores já em desvantagem. Com isso, os processos participativos poderiam gerar novas formas de exclusão e acarretariam riscos de manter o poder de decisão nas mãos de um pequeno grupo. Mais importante do que o processo participativo, no entanto, são os seus resultados e as características desse processo.

Segundo Brugué e Vallès (2005), a Teoria Deliberativa considera que todo processo deliberativo deve satisfazer quatro características principais, quais sejam: 1a) 0 processo deliberativo deve garantir que todas as vozes presentes sejam ouvidas, ou seja, ele deve ser inclusivo; 2a) O processo deliberativo tem de ser aberto a todos e ser compreensível e acessível, e para isso o público deve possuir todas as informações necessárias para a deliberação; 3a) A deliberação não é um bate-papo informal, logo, as decisões derivadas de um 
processo deliberativo participativo devem ser eficazes e culminar em decisões concretas; 4a) O processo deliberativo deve gerar economia moral de desacordo. De acordo com este princípio, devemos maximizar o respeito mútuo e minimizar as diferenças.

Avaliar a capacidade deliberativa dos Conselhos e o seu impacto no processo de produção das políticas públicas é uma tarefa difícil e que ainda é feita apenas de maneira experimental. Isso se deve a dois fatos, o primeiro por se tratar de experiências muito recentes e o segundo pela dificuldade em estabelecer parâmetros para análise. Analisando criticamente a literatura, no entanto, o que se constata é a ideia de que os Conselhos não estão seguindo sua vocação deliberativa. Entre os principais motivos apresentados, a grande maioria dos estudos aponta para a baixa capacidade de inovação das políticas públicas a partir da participação da sociedade civil nos Conselhos, o que indica que essa participação assume contornos mais reativos que propositivos (TATAGIBA, 2002).

\section{PROCEDIMENTOS METODOLÓGICOS}

Utilizando de abordagem qualitativa buscou-se realizar um estudo de casos múltiplos e interpretativos dos Conselhos Municipais de Saúde de Minas Gerais. Apoiou-se em uma pesquisa em profundidade com perspectiva de servir como estudo preliminar para outros trabalhos mais diversificados. Acredita-se que trabalhando com múltiplos casos tem-se a possibilidade de desenvolver uma análise e uma avaliação mais exaustiva e detalhada, o que permite atender às propostas deste estudo. A escolha dos ConseIhos de Saúde como objeto de análise levou em consideração o fato de serem instituições formalizadas e incorporadas legalmente ao processo de gestão de saúde no Brasil. Além disso, foram escolhidos como casos pelo seu potencial de inserção da sociedade nas decisões públicas, por representar uma das experiências brasileiras mais consolidadas em termos de instituições participativas e por ser um valioso instrumento coletivo de exercício de cidadania e engajamento cívico do povo brasileiro. De acordo com Yin (2014), a preferência pelo uso do método do estudo de caso deve ser dada quando é possível se fazer observações diretas e entrevistas sistemáticas, em uma unidade que se analisa profundamente. Para o estudo de casos múltiplos, as unidades de análise foram os Conselhos Municipais de Saúde de Minas Gerais situados nas macrorregiões de planejamento, segundo distribuição oficial feita pela Secretaria Estadual de Saúde de Minas Gerais (SES/MG), conforme divisão exposta na Figura 1.

A expectativa é contribuir com reflexões críticas que possam melhorar a compreensão do que se passa nos Conselhos de Saúde das 13 macrorregiões já definidas como estratégicas pelo governo de Minas, analisando o funcionamento e os papéis desenvolvidos pelos Conselhos em termos de gestão da saúde pública. Na impossibilidade de aprofundar os estudos em todas as cidades que compõem as macrorregiões, optou-se por estudos de casos em 7 cidades consideradas polos macrorregionais em saúde e que autorizaram acesso às informações e dados pertinentes à pesquisa realizada. Estas cidades foram eleitas considerando o maior grau de complexidade para gerir a política de saúde regional, como o maior número de cidades agregadas, maior volume de demandas regionais na área da saúde e maior contingente populacional. São elas: Uberlândia, Uberaba, Diamantina, Ponte Nova, Juiz de Fora, Barbacena e Divinópolis.

Figura 1 - Macrorregiões de Planejamento em Saúde de Minas Gerais 


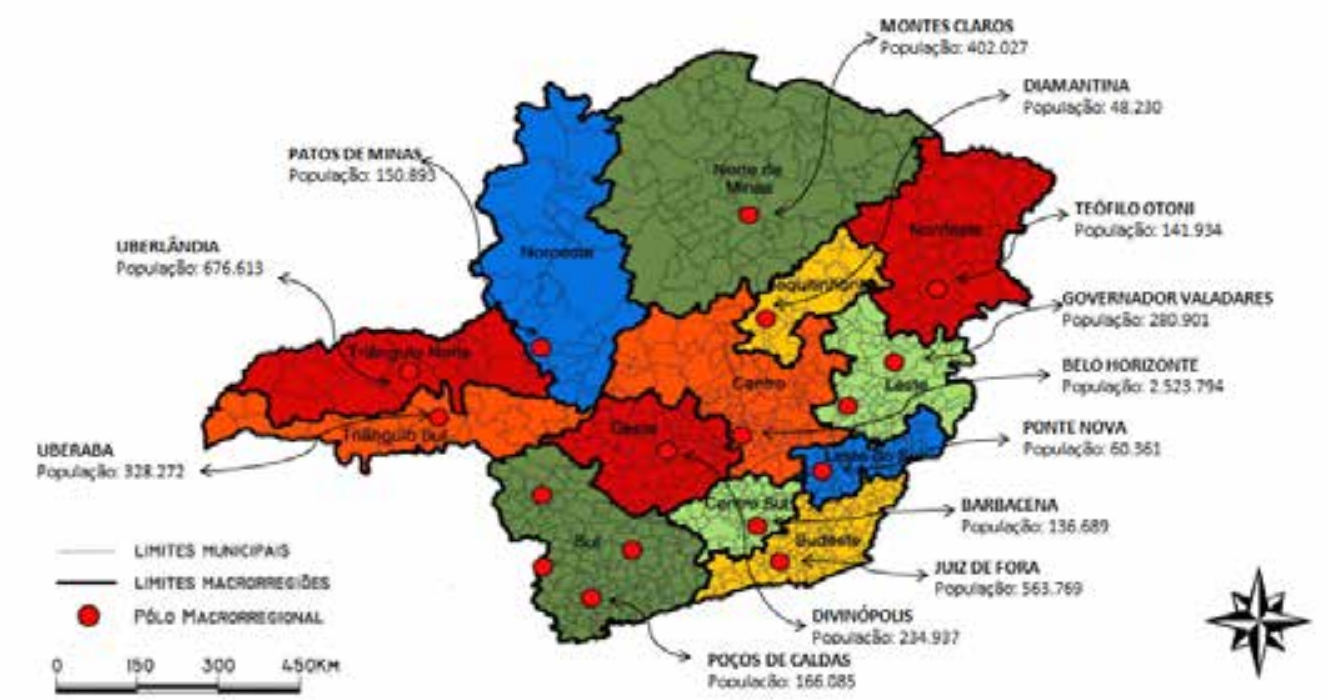

MAPA 1: MACRORRECHOES DE SALDE DE MINAS GERATS

FONTE: Secretaria Estadual de Saúde de Ninas Gerais (SES MG)- Pano Direter de Regienalsaplo da Saude 2003/2006; Org StLVA, C. B, 2008

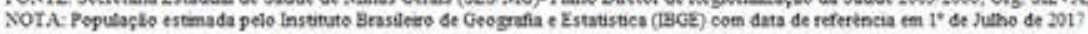

rormas de ubtençao de vados e intormaçoes

Os dados e informações obtidos para a elaboração da pesquisa foram de origem secundária e primária. Os secundários foram buscados por intermédio de documentos oficiais (estatuto, normas, procedimentos e processos de trabalho, entre outros) já consolidados e em poder dos Conselhos Regionais estudados. Os dados/informações primários foram obtidos por meio da técnica de entrevista, reuniões, plenárias, fóruns e depoimentos que permitiram corroborar os resultados da presente pesquisa e oferecer alguns pontos de vista, o que, segundo Vergara (2016), são técnicas de investigação importantes e utilizadas com frequência nas pesquisas qualitativas. A análise temporal desta pesquisa baseou-se na busca dos resultados, por intermédio de entrevistas in loco, participação em fóruns e reuniões organizados pelos Conselhos de Saúde durante o período de janeiro a dezembro de 2018.

\section{Etapas de Operacionalização das Entrevistas, Observação e Análise de Conteúdo}

Dentro da perspectiva da pesquisa qualitativa, a entrevista apresentou-se como um dos instrumentos para a coleta de dados/informações e pode ser considerada uma das principais fontes de dados para este estudo de multicasos. Optou-se por utilizar a entrevista semiestruturada, individual e em profundidade, com a finalidade de obter dos entrevistados opiniões com maior riqueza de detalhes, para que o próprio sujeito de pesquisa dê sentido aos seus atos e as suas ações. De acordo com Lakatos e Marconi (1996) e Vergara (2016), trata-se de uma técnica em que o entrevistador segue um roteiro previamente elaborado, mas que pode sofrer alterações, o que exige do pesquisador domínio do referencial teórico. Este tipo de entrevista procura profundidade/intensidade nas respostas dos entrevistados e não a mera quantificação ou representação estatística das informações levantadas. 
Inicialmente, esteve à disposição um roteiro de perguntas para conduzir as entrevistas, com questões agrupadas em categorias eixo de análise, definidas a partir do embasamento teórico, em um esforço para compreender como funcionam os Conselhos, quais são as características das pessoas que os compõem e para mapear os efeitos esperados com as suas ações e decisões. Por ser semiestruturada, entretanto, foi garantido o espaço necessário para que o(a) entrevistado(a) se manifestasse de acordo com a sua livre construção de sentido. As entrevistas foram gravadas para permitir a reprodução exata dos depoimentos e para possibilitar ao pesquisador a condição de um espectador atento à fala do entrevistado. Com fins de análise interpretativa, as entrevistas foram transcritas, codificadas e categorizadas, empregando a Técnica de Análise de Conteúdo (BARDIN, 2009), cuja ênfase recai no conteúdo manifesto do discurso e nos argumentos apresentados. $\mathrm{O}$ anonimato foi garantido.

A “Observação Não Participante" complementou as informações obtidas via documentos e nas gravações das entrevistas, sendo feita em visitas, durante as entrevistas, participação em fóruns e em reuniões das plenárias (ordinárias e extraordinárias) dos Conselhos pesquisados, sendo necessário que o pesquisador atuasse como espectador atento (VERGARA, 2016). A técnica de observação foi importante e ofereceu várias vantagens como: possibilidade de obter informações diretas sobre o comportamento dos(as) conselheiros(as); permitir compreender melhor a situação investigada; fornecer boas oportunidades de verificar o fenômeno estudado in loco; acontecer de maneira natural, não sendo necessária uma estrutura formal estabelecida.

Já a Técnica de Análise de Conteúdo foi utilizada como técnica principal para proporcionar a interpretação das informações e dados coletados. Bardin (2009, p. 31) a define como "um conjunto de técnicas de análise das comunicações". Mais do que um instrumento, é um conjunto de técnicas e procedimentos marcado por uma grande disparidade de forma e adaptável a um amplo campo de aplicação. Esta técnica é uma entre as diferentes formas de interpretar o conteúdo de um texto. Para a realização da análise de conteúdo as categorias-eixo e subcategorias foram preliminarmente estabelecidas com base na literatura sobre participação social e democracia deliberativa.

\section{APRESENTAÇÃO E ANÁLISE DOS RESULTADOS}

Nesta seção são apresentados os principais resultados da pesquisa, definidos com base nas entrevistas feitas nos encontros presenciais e nos contatos via Internet/telefonemas com presidentes e/ou representantes titulares e suplentes dos Conselhos de Saúde Municipais que se dispuseram a colaborar com o presente estudo. Dos 13 Conselhos polos de saúde potenciais a serem pesquisados, somente 7 aceitaram participar. De acordo com a estrutura dos roteiros de entrevista, inicialmente foram abordadas questões acerca da caracterização dos Conselhos e suas formas de escolha dos representantes. Foram abordadas questões referentes ao gênero, idade, renda, escolaridade e sobre trajetórias pessoais até chegar à função que exercem atualmente nos Conselhos de Saúde.

Quanto ao sexo dos conselheiros de saúde, entre os 7 Conselhos analisados, estão sob a presidência de mulheres os conselhos de Barbacena, Diamantina, Ponte Nova, Uberlândia e Uberaba. Os Conselhos de Saúde de Divinópolis e Juiz de Fora são presididos por membros do sexo masculino. Já em relação à ocupação atual dos represen- 
tantes dos Conselhos, o representante de Divinópolis denomina-se um microempreendedor, a de Barbacena uma professora aposentada, em Diamantina a representante é enfermeira e em Uberaba a conselheira representante é dentista. No Conselho de Juiz de Fora o presidente é bacharel em Direito e servidor público municipal, assim como em Uberlândia a representante conselheira é assessora parlamentar. Diferentemente dos profissionais mais tradicionais, o Conselho de Saúde de Ponte Nova é presidido por uma mulher que exerce a função de presidente de um sindicato de trabalhadores domésticos no município.

Em referência à idade dos presidentes dos Conselhos de Saúde, 28,6\% têm entre 40 a 50 anos (Divinópolis e Uberlândia), 28,6\% possuem entre 50 e 60 (Barbacena e Uberaba), outros $28,6 \%$ estão com idade superior a 60 anos (Juiz de Fora e Ponte Nova) e 14,2\%, nesse caso, apenas Diamantina possui um representante com idade entre $30 \mathrm{e}$ 40 anos. Ainda permeando as análises caracterizadoras dos conselheiros entrevistados, foram inquiridos sobre o nível de escolaridade de cada conselheiro. Os resultados apontam que $57 \%$ deles possuem Pós-Graduação em alguma área específica (representantes de Divinópolis, Barbacena, Diamantina e Uberaba), os demais presidentes dos ConseIhos possuem curso superior completo (Juiz de Fora), superior incompleto (Uberlândia) e Ensino Médio completo (Ponte Nova). No que concerne à renda dos conselheiros de saúde entrevistados, os níveis salariais dos entrevistados foram diversos: $28,6 \%$ ganham de 8 a 10 salários mínimos (conselheiros de Barbacena e Uberaba), outros 28,6\% entre 5 e 7 salários mínimos (Juiz de Fora e Divinópolis), também 28,6\% entre 2 e 4 salários mínimos (Diamantina e Uberlândia) e apenas a conselheira de Ponte Nova (14,2\%) possui uma renda de até um salário mínimo.

A trajetória no tempo de atuação dentro dos Conselhos de Saúde e outros Conselhos, bem como em outras entidades participativas, pode implicar resultados diferentes quanto a atitudes sobre ações na gestão dessas instituições. Ressalta-se que em todos os Conselhos analisados nesta pesquisa, todos os(as) conselheiros(as) já estavam há mais de 2 anos atuando como membros. Na presidência do Conselho de Saúde de Barbacena a atual presidente já é membro da equipe há 8 anos, e há 4 anos exerce a presidência, observando-se que também desempenhou papel em Conselhos de Meio Ambiente e no da Mulher. Diferentemente, no caso de Diamantina, a presidente do respectivo Conselho ocupa a função há quase 2 anos (meados de 2017 a dezembro de 2018), não fez parte de outro Conselho de classe ou instituições sociais. Em Divinópolis nota-se também uma semelhança referente ao tempo de atuação do conselheiro presidente. Nesse caso, ele atua em outras esferas de Conselhos entre 3 e 4 anos, e especificamente no Conselho de Saúde está há mais de um ano à frente da gestão.

Entre os Conselhos pesquisados, os presidentes dos Conselhos de Juiz de Fora e Uberlândia estão há mais tempo atuando na área pública e em Conselhos de outras esferas. O conselheiro de Juiz de Fora atua desde 1998 como conselheiro de saúde no município e esteve à frente quase que concomitantemente como secretário municipal de saúde. Em Uberlândia, a conselheira atua desde 1997 no Conselho Distrital de Saúde, e desde 2003, propriamente no Conselho de Saúde. Nesses Conselhos mencionados, o fator "tempo à frente da gestão" se destaca, e essas constatações podem ocasionar percepções e relações diferentes entre si, no que diz respeito a critérios de deliberação participativa e outras características próprias inerentes à dinâmica institucional dos Con- 
selhos de Saúde. Finalizando acerca do tempo de participação em Conselhos de classe e em especial nos Conselhos de Saúde, a conselheira de saúde presidente em Uberaba atua nesta área há mais de 6 anos, e à frente da gestão há 4 anos, atuando também no Conselho Municipal dos Direitos da Criança e do Adolescente (CMDCA). Diferentemente dos casos até aqui apresentados, a conselheira de saúde em Ponte Nova atua há 26 anos no mesmo Conselho de Saúde, e há 4 anos preside a respectiva instituição. Foram também indagados acerca de qual segmento cada membro representava, e constatou-se que os presidentes entrevistados pertencentes aos Conselhos de Saúde representam predominantemente os segmentos "profissionais de saúde" e "usuários do SUS".

\section{Aspectos Deliberativos e de Tomada de Decisão na Percepção dos Conselheiros}

Aqui são apresentados os resultados referentes às percepções reais dos conseIheiros de saúde, representantes dos Conselhos de Saúde dos municípios mineiros de Barbacena, Diamantina, Divinópolis, Juiz de Fora, Ponte Nova, Uberaba e Uberlândia. Por meio da utilização de técnicas de análise de conteúdo, foram analisadas as respostas das entrevistas feitas com conselheiros e conselheiras de saúde em Minas Gerais. É notório, em quase todos os casos, existirem preocupações primordiais com a qualidade da saúde local/regional e sua importância para a população em geral. As características mais relevantes que podem ser captadas de cada Conselho podem ser percebidas de forma bem clara. Em Barbacena considera-se que o Conselho de Saúde exerce relevância como papel fiscalizador e propositivo de políticas públicas para a população; já em Diamantina a experiência profissional da conselheira foi relevante para dar início à melhoria da saúde por meio das ações do Conselho. Tanto nos Conselhos de Divinópolis quanto em Ponte Nova o papel participativo de cada conselheiro(a) na execução de investimentos na área da saúde facilita o acesso do cidadão aos serviços de saúde pública.

Diferentemente dos outros Conselhos estudados, em Juiz de Fora a experiência do conselheiro como secretário municipal de Saúde pode ter tido influência na sua posição social, uma vez que ele relata sempre ter feito críticas ao funcionamento não só do Conselho, mas também da estrutura de atendimento à saúde pública do município.

Primeiro, vou deixar claro, considero muito importante, apesar de que, assim, nós não temos perna pra isso, mas a gente precisava discutir mais a política como um todo. Porque às vezes nós ficamos muito pontuais, muito focados em um único problema. Nós temos uma pauta recorrente, que é a demanda reprimida nas consultas de especialidades (...) nós não estamos conseguindo resolver, porque você não tem mais a oferta de consulta. Com a chegada da atenção primária com a ideia de que o médico da atenção primária ele é um médico de saúde coletiva e a comunidade chamada na época de generalista, e que $80 \%$ das demandas do cidadão deva ser de atenção primária. Então, nós temos esse problema da demanda reprimida de endócrino, oftalmologia, ortopedia. Então, a gente não vai conseguir, mas não vamos desistir da pauta. Então se disser assim: "Ah, nós temos um problema de recursos humanos"... Água mole em pedra dura, tanto bate até que fura, ou seca a água; mas a gente não vai deixar secar a água. Então nós estamos em uma batalha com a Secretaria de Saúde e com a Administração Municipal - não só essa, como todas que vão passando - de recursos humanos. O próprio Ministério Público tem uma dificuldade tremenda. Então a gente tem essa questão da demanda reprimida, mas nós vamos deixar de falar? Não. A gente tá hoje aí discutindo. Ah, 
o horário de fechar a unidade de saúde! Por que tem que fechar a unidade mais cedo? Tem gente querendo fechar a unidade 1 hora da tarde e fazer horário corrido. Aí joga para o Conselho decidir, aí eu falo: Não, isso não é competência nossa; isso é gestão. Então, assim, nós somos uma ferramenta importante. Ontem veio uma moça aqui e me pediu pra mandar uma demanda para o presidente da Cesama de uma tampa de PVC nos bueiros... isso não é problema nosso, ponto! Não é!? E se uma pessoa cair ali? Foi gerada através de um problema de infraestrutura, mas que caiu no colo da saúde, porque ela pode ter uma fratura, ela pode sofrer uma pancada na cabeça (ENTREVISTA CONSELHEIRO - JUIZ DE FORA, 2018).

Nos casos de Ponte Nova e Uberlândia ficou evidente que o papel do Conselho é ajudar as pessoas que necessitam de acesso à saúde pública local/regional.

Muito importante o Conselho na cidade, e o meu interesse em participar do ConseIho é pra poder ajudar um pouco mais a comunidade porque a comunidade depende muito desse conselho (ENTREVISTA CONSELHEIRO - PONTE NOVA, 2018).

Muito importante. Devido ao trabalho voluntário junto a pastoral da saúde há pacientes acamados, vi a necessidade de lutar por melhorias de acesso e assistência e descobri Conselhos de Saúde, e me apaixonei (ENTREVISTA CONSELHEIRO - UBERLÂNDIA, 2018).

As principais opiniões e percepções dos(as) conselheiros(as) de Uberaba, Barbacena, Diamantina e Divinópolis foram destacadas a seguir, corroborando o que foi descrito anteriormente:

Porque sou uma entusiasta do SUS e por trinta e cinco (35) anos atuei na saúde pública no atendimento clínico e gestão (ENTREVISTA CONSELHEIRA - UBERABA, 2018).

Sim, porque a gente vai regular o funcionamento, a gente aprova, e propõe novas coisas na cidade, na saúde, para a melhoria, para um melhor desempenho. 0 conselho tem papel fiscalizador, deliberativo e propositivo também, é o que está previsto na lei. Aqui a gente faz um controle social [...]. Antes eu participava do sindicato dos trabalhadores da educação, tem a minha área, e a gente viu que o controle tem que ser feito pelos trabalhadores [..], porque as conferências elas são espaço democrático em que a população pode propor políticas públicas, por que o mais importante são as políticas públicas e não as políticas de governo[...]. Por que senão o governo passa e a política não acontece, então por isso que eu acho importante participar para a gente garantir que a gente tenha políticas públicas para todos os setores da sociedade (ENTREVISTA CONSELHEIRO - BARBACENA, 2018).

Importantíssimo. Sou enfermeira há 11 anos, em minha atuação profissional tive a possibilidade de trabalhar nos três níveis de atenção à saúde e percebo a fragilidade do nosso sistema de saúde com uma rede fragmentada, diante essa experiência, a busca constante por novos conhecimentos e aprendizados e por princípios de cidadania, fez-me refletir e questionar sobre nossas políticas públicas, assim o Conselho veio como meio de tentar compreender e buscar caminhos de fortalecimento desse sistema (ENTREVISTA CONSELHEIRA - DIAMANTINA, 2018).

Sim, muito importante, o Conselho por ser deliberativo na saúde ele consegue fazer com que a gestão faça os investimentos no local mais adequado relativo à saúde do município, né. Então se não tivesse o Conselho o gestor poderia agir da forma que ele bem quisesse, tornaria isso um mal para saúde né do cidadão (ENTREVISTA CONSELHEIRO - DIVINÓPOLIS, 2018). 
A forma de inserção desses representantes nos Conselhos de Saúde é bastante relevante quando se estuda o modelo deliberativo de gestão. Entre os sete Conselhos de Saúde analisados, os de Barbacena, Juiz de Fora, Ponte Nova, Uberaba e Uberlândia tiveram seus presidentes eleitos como representantes por outros membros do Conselho, o que de certa forma considera-se a via mais democrática para escolha dos seus gestores. Diferentemente, os conselheiros de saúde presidentes em Divinópolis e Diamantina foram indicados por outros conselheiros.

Quanto à atuação dos Conselhos, os seus representantes em geral compreendem que exista um papel principal de fiscalização do poder público, de realização de reuniões, de trabalho e melhoria em prol dos seus representados. No caso de Barbacena, Diamantina e Divinópolis puderam ser identificadas visões diferenciadas acerca da atuação dos conselhos gestores de saúde locais. Essas visões representam muitas vezes o papel que cada organização exerce, levando em conta suas regionalidades e suas prioridades locais junto a população. Nos casos de Barbacena, Diamantina e Divinópolis constataram-se definições diferentes acerca da atuação. No caso de Barbacena, os problemas burocráticos e documentais foram relevantes para descrever a atuação do respectivo Conselho local, e parece ser a principal preocupação. Em Diamantina a atuação percebida pelo seu representante teve um aspecto de maior ênfase com o papel da participação ativa da população e dos membros para o devido exercício de suas atividades. Já no caso de Divinópolis a explicação para sua atuação é deixada de lado, uma vez que logo é alterada por uma queixa ou problema pelo qual o Conselho local provavelmente vem passando, nesse caso, a falta de recursos apresentada pelos trechos das entrevistas que estão evidenciadas a seguir.

Atualmente o conselho tem conseguido colocar em dia toda a documentação, então tem muita coisa que conselho precisa, esses relatórios anuais, prestação de contas, essas comissões, fazer as conferências, fazer as reuniões, fazer as atas... Toda essa documentação, antes de a gente entrar no conselho, elas eram todas atrasadas, fora de época e tal... A gente conseguiu colocar toda documentação em dia, o conselho tem toda documentação, ele é fiscalizado pelo Ministério da Saúde, pelo Estado, então ele tem tudo em dia. A gente tem uma secretária para ajudar nessa parte, porque os conselheiros não são remunerados, são voluntários e aí então a gente tem aqui essa estrutura para fazer o conselho funcionar. Então o conselho conseguiu isso e também a gente conseguiu uma parceria com a gestão pública em que o secretário é mais parceiro do que adversário, então com isso a gente conseguiu caminhar bastante na melhoria, ainda falta muita coisa, mas a gente conseguiu melhorar algumas ações em saúde aqui na cidade (ENTREVISTA CONSELHEIRO - BARBACENA, 2018).

O Conselho tem tido crescimento nesse período em que tenho participado, há frequência dos conselheiros, participação ativa da Secretaria Municipal de Saúde, porém há muito a ser conquistado e reconhecido por parte da sociedade como um todo (ENTREVISTA CONSELHEIRO - DIAMANTINA, 2018).

Ainda levando em conta o papel de caráter atuante dos Conselhos de Saúde, em Divinópolis, o entrevistado afirma que "nós temos feito um bom trabalho, a gente tem se esforçado muito, o maior obstáculo atualmente tem sido a falta de recursos" (ENTREVISTA CONSELHEIRO - DIVINÓPOLIS, 2018), tornando-se negativo para uma atuação 
mais efetiva do Conselho. Já o representante de Juiz de Fora alega limitações e problemas como a falta de medicamentos e profissionais qualificados para resolução de problemas mais graves de saúde que afetam a comunidade em geral, quais sejam:

[...] então a nossa atuação, na medida do possível, no Conselho eu sou suspeito pra falar porque tenho que fazer acontecer, enquanto Secretário Executivo do Conselho. Então dentro das nossas capacidades, das limitações, dentro daquilo que a gente pode agir, a gente trabalha, a gente age. Tem muita demanda que vem dos Conselhos locais em função das unidades, falta de medicamento, falta de profissional, né? [...] (ENTREVISTA - JUIZ DE FORA, 2018).

A atuação do Conselho de Ponte Nova, segundo a visão da sua representante, também revela limitações, e uma compreensão da necessidade de se avançar com processos e tarefas: "Olha, eu avalio o seguinte, tem muita coisa que ainda precisa ser feita, mas eu avalio muito bem em vista de outros conselhos" (ENTREVISTA - PONTE NOVA, 2018). Nos casos de Uberlândia, as alegações e problemas também foram evidenciados, assim como em Divinópolis e Juiz de Fora, alegando problemas de capacitação de pessoal, embora assumam que a atuação do Conselho não fica impedida de realizar seu papel: "infelizmente a falta de tempo, de capacitação e outros fatores acaba impedindo de ter a maioria de conselheiros atuantes, mas isto não impede na luta e resultados positivos" (ENTREVISTA - UBERLÂNDIA, 2018). Em Uberaba, a representante do Conselho, diferentemente dos outros, aponta para uma atuação negativa em relação aos outros casos, alegando problemas institucionais graves que se desviam do que deveria ser executado dentro do processo de deliberação e participação: "Atuação incipiente, focada principalmente no interesse pessoal, corporativo e político" (ENTREVISTA - UBERABA, 2018).

Acerca do processo democrático deliberativo, segundo constatações dos principais autores que tratam do assunto (BRUGUÉ; VALLÈS, 2005; SILVA et al., 2014; CORREIA, 2005; O'DONNELL, 1994; DAHL, 1989), foram encontradas respostas para as questões relacionadas aos objetivos das reuniões, alcance das metas propostas, e principalmente o processo de participação e comunicação dos conselheiros representantes da sociedade civil. As reuniões, plenárias, fóruns e conferências são importantes momentos de participação social, de deliberação de ações das quais se cumpre ritos processuais, dos quais também ocorre a resolução dos problemas de saúde levados pela população bem como pela mesa diretora e membros do Conselho. A periodicidade das reuniões é uma variável fundamental que pode inclusive explicar a efetividade dos resultados das ações tomadas dentro dos Conselhos, bem como da aproximação da população com seus representantes, facilitando a eficácia do processo deliberativo e de participação social.

Nos sete casos analisados, apenas os Conselhos de Saúde de Barbacena e Juiz de Fora têm a periodicidade quinzenal de reuniões, enquanto os de Diamantina, Divinópolis, Ponte Nova, Uberaba e Uberlândia realizam reuniões mensalmente. Um ponto que deve ser levado em conta é que apesar de a periodicidade das reuniões estar pré-agendada, em todos os casos existe a possibilidade de abertura de reuniões extraordinárias para discussão e deliberação de pautas urgentes para a população ou referente às atividades do Conselho. Ainda, com ênfase em "como e o que se discute", cada Conselho de Saúde, como referido anteriormente, tem satisfações e insatisfações próprias, problemas locais específicos e prioridades pontuais. Nesses casos foram apresentados 
os principais temas tidos como prioritários, que estão sempre em debate e discussão, segundo a visão dos Conselhos e dos conselheiros representantes. Em muitos dos casos esses problemas referem-se a questões de cunho burocrático, pouco ideológico e muito das suas rotinas locais e prioritárias.

No Quadro 1 encontram-se os principais temas debatidos nas reuniões dos Conselhos de Saúde, que são levados a discussões e deliberações, bem como a totalidade de gastos em saúde pública nos municípios-polo estudados correspondente ao período de 2011 a 2018.

\section{Quadro 1 -Temas debatidos nos Conselhos de Saúde e gastos} em saúde pública nos municípios-polo

\begin{tabular}{|c|c|c|}
\hline Município-Polo & Atividades do Conselho de Saúde & $\begin{array}{l}\text { Gastos com Saúde } \\
-2011 \text { a } 2018\end{array}$ \\
\hline Barbacena & $\begin{array}{l}\text { Prestação de contas } \\
\text { Demandas do gestor e financeira } \\
\text { Questões emergenciais à saúde }\end{array}$ & $\mathrm{R} \$ \mathbf{4 7 4 . 4 5 0 . 2 5 4 , 5 7}$ \\
\hline Diamantina & $\begin{array}{l}\text { Planejamento da saúde } \\
\text { Projetos de pesquisa e orçamentário } \\
\text { Denúncias }\end{array}$ & $\mathrm{R} \$ 61.007 .027,36$ \\
\hline Divinópolis & $\begin{array}{l}\text { Planos municipais de saúde } \\
\text { Gastos em Saúde e Infraestrutura }\end{array}$ & $\mathrm{R} \$ \mathbf{4 5 4 . 9 5 9 . 5 0 3 , 6 6}$ \\
\hline Juiz de Fora & $\begin{array}{l}\text { Cronograma de ações } \\
\text { Prestação de contas e demandas }\end{array}$ & $\mathrm{R} \$ 1.626 .423 .833,15$ \\
\hline Ponte Nova & $\begin{array}{l}\text { Demandas de atendimentos } \\
\text { Informes gerais }\end{array}$ & $\mathrm{R} \$ 191.705 .130,19$ \\
\hline Uberaba & $\begin{array}{l}\text { Requerimentos de saúde do Ministério Público, } \\
\text { Secretaria de Saúde e trabalhadores }\end{array}$ & $\mathrm{R} \$ 627.592 .824,77$ \\
\hline Uberlândia & $\begin{array}{l}\text { Todos os assuntos relacionados à saúde, como } \\
\text { pessoas e recursos } \\
\text { Documentos e regulamentações }\end{array}$ & $\mathrm{R} \$ 1.078 .902 .535,18$ \\
\hline
\end{tabular}

Fonte: Pesquisa de campo e Portal da Transparência/Ministério da Saúde, 2018.

Nesse sentido, é possível constatar que cada Conselho possui uma abrangência de temas que são específicos e inerentes às questões locais/regionais de discussões e prioridades, especialmente quando se pensa nos gastos públicos com a saúde nos municípios das macrorregiões pesquisadas. A única uniformidade de explanações nesses casos é que se pode detectar que dentro do ambiente dos Conselhos ocorrem debates de temas diversos, o que elimina o caráter cartorial e ritualístico dos Conselhos gestores de saúde pública e os diferencia de outras organizações. As preocupações com prestação de contas, demandas setoriais da saúde e questões emergenciais foram os principais temas apresentados que são levados a debate, segundo a representante de Barbacena. Os Conselhos de Diamantina e Divinópolis levam na pauta dos debates questões ligadas, principalmente, ao planejamento municipal de saúde, e que na maioria das vezes são coadjuvantes na sua formulação e definição de metas e prioridades. Os conselhos de Juiz de Fora e Ponte Nova, diferentemente dos demais apresentados, não expuseram detalhadamente quais assuntos são debatidos nas reuniões e fica evidenciado nos trechos das entrevistas que em regra os temas principais debatidos ficam restritos a generalizações como: "Já fiz o calendário do ano do Conselho Municipal todinho respeitando 
os feriados; teve um feriado aí que eu engoli, passei batido, era feriado e eu coloquei reunião, entendeu?" (ENTREVISTA - JUIZ DE FORA, 2018); "Tem várias coisas que não são os mesmos assuntos não" (ENTREVISTA - PONTE NOVA, 2018).

Nos casos de Uberaba e Uberlândia, dois Conselhos da mesma macrorregião do Triângulo Mineiro, as principais pautas discutidas referem-se a requerimentos vindos da Prefeitura e do Ministério Público. De certa forma, esses dois Conselhos têm um viés mais burocrático no que tange à atenção extrema a regulamentações, e que diminui, ou pelo menos não fica evidente, a participação e discussão de pautas advindas da população local, uma vez que segundo a visão dos entrevistados, os assuntos relacionados aos órgãos públicos estão em pauta com bastante frequência.

Quanto ao funcionamento do processo deliberativo de tomadas de decisão, o Quadro 2 evidencia de forma clara o modo como ocorre o processo deliberativo, o tempo para discussão e os procedimentos de participação externa.

Quadro 2 - Funcionamento do processo decisório deliberativo e participação social

\begin{tabular}{|c|c|c|c|}
\hline Conselho de Saúde & Tomadas de Decisão & Tempo de Aprovação & Participação Externa \\
\hline Barbacena & \begin{tabular}{|l|} 
Proposição \\
Discussão \\
Parecer técnico \\
Votação \\
\end{tabular} & Período das reuniões & $\begin{array}{l}\text { Possui direito a } \\
\text { sugestões, mas não a } \\
\text { voto }\end{array}$ \\
\hline Diamantina & \begin{tabular}{|l|} 
Agendamento \\
Aprovação \\
Discussão \\
Votação \\
\end{tabular} & $\begin{array}{l}\text { Aprovação no dia } \\
\text { Pautas complexas } \\
\text { demandam mais } \\
\text { tempo }\end{array}$ & Participações pontuais \\
\hline Divinópolis & \begin{tabular}{|l|} 
Apresentação \\
Pareceres \\
Votação do colegiado
\end{tabular} & $\begin{array}{l}\text { Até } 4 \text { meses assuntos } \\
\text { complexos }\end{array}$ & $\begin{array}{l}\text { Existe participação } \\
\text { externa }\end{array}$ \\
\hline Juiz de Fora & $\begin{array}{l}\text { Recebimento de } \\
\text { demanda } \\
\text { Votação } \\
\end{array}$ & Até 90 dias & $\begin{array}{l}\text { Possuem abertura da } \\
\text { palavra no plenário }\end{array}$ \\
\hline Ponte Nova & $\begin{array}{l}\text { Votação pela } \\
\text { assembleia }\end{array}$ & Até 15 dias por pauta & \begin{tabular}{|l|} 
Permitido, exceto \\
em reuniões \\
extraordinárias
\end{tabular} \\
\hline Uberaba & \begin{tabular}{|l|} 
Reunião \\
Troca de \\
documentação \\
Emissão de relatórios \\
Análise técnica \\
Votação \\
\end{tabular} & Duração da reunião & $\begin{array}{l}\text { Aberto a visitações e } \\
\text { participações pontuais }\end{array}$ \\
\hline Uberlândia & \begin{tabular}{|l|} 
Discussão \\
Formação de \\
comissões \\
Relatório técnico \\
Parecer \\
Votação \\
\end{tabular} & $\begin{array}{l}\text { Não existe prazo } \\
\text { definido }\end{array}$ & $\begin{array}{l}\text { Aberto à opinião, mas } \\
\text { sem direito a voto }\end{array}$ \\
\hline
\end{tabular}

Fonte: Resultados da pesquisa, 2018. 
Nota-se que, de forma bem clara e prática, o funcionamento do processo de participação social e deliberação dentro dos Conselhos de Saúde das sete macrorregiões do Estado de Minas Gerais encontram-se parcialmente associados à literatura sobre o assunto (BRUGUÉ; VALLÈS, 2005; SILVA et al., 2014; CORREIA, 2005; O’DONNELL, 1994; DAHL, 1989). Nesta etapa da pesquisa foram encontrados resultados que identificaram como ocorre o processo de tomadas de decisão coletivas dentro dos Conselhos de Saúde, bem como o tempo de aprovação das pautas apresentadas, seja por membros do Conselho, seja pela população participante, e principalmente o modo de aceitação à participação externa da população em geral.

De maneira adequada com os princípios da Teoria Democrática Deliberativa, no que diz respeito ao processo de tomadas de decisão coletivas, todos os sete ConseIhos de Saúde analisados têm o objetivo final de chegar às votações das pautas apresentadas. Também fica evidente que os conselheiros representantes têm certo domínio sobre o processo de decisão até o momento da votação. A grande maioria considera que antes de as pautas serem votadas devem passar por processos de discussão mais detalhados, bem como pela divulgação de relatórios técnicos para a compreensão das pautas, e só então deve-se realizar a votação. Como demonstrado em uma das falas da representante do Conselho de Saúde de Uberaba, que descreveu sistematicamente o processo de tomadas de decisão:

A Mesa Diretora se reúne uma semana antes da reunião, define a pauta com os assuntos a serem deliberados na reunião ordinária e encaminha a pauta, juntamente com a convocação, sete dias antes da reunião, via e-mail, são encaminhadas juntamente a documentação sobre o assunto em pauta, para conhecimento e análise prévia dos conselheiros, durante este período pré-reunião a câmara técnica responsável pelo assunto em pauta se reúne, analisa e emite relatório técnico sobre o assunto que é apresentado ao plenário do Conselho durante a reunião ordinária. Após esta apresentação os conselheiros e demais participantes têm direito à fala e após as mesmas o assunto é colocado para votação dos conselheiros titulares (ENTREVISTA - UBERABA, 2018).

Por outro lado, a conselheira representante de Ponte Nova, diferentemente dos demais, resumiu em sua frase da entrevista e demonstrou pouco conhecimento ao ser instada a descrever o processo deliberativo de tomada de decisão: "É votação, passa pela assembleia e aí é votado" (ENTREVISTA - PONTE NOVA). Nesse caso, essa resposta também pode ser um reflexo da generalidade do conhecimento do funcionamento dos Conselhos, uma vez que não foi encontrado detalhamento das propostas dos temas debatidos neste respectivo Conselho de Saúde, na visão da sua presidente conselheira de saúde.

No que diz respeito ao tempo de aprovação das propostas debatidas e apresentadas nos plenários dos Conselhos de Saúde locais, os Conselhos de Uberaba, Diamantina e Barbacena estão em conformidade com a eficácia e eficiência das normas regulamentares, em relação ao funcionamento mais ágil e de tramitação de proposta. É importante, portanto, salientar que não são todos os casos nos quais se torna possível avaliar propostas e deliberar ações no mesmo dia, uma vez que as propostas mais complexas demandam tempo de análise, uma abertura maior ao diálogo de todas as partes interessadas e que na prática convertam-se em resultados efetivos, permitindo efetivar 
propostas sem vícios e vieses que possam prejudicar consequentemente as políticas públicas de saúde e as ações de saúde que são levadas à disposição da população local. Os Conselhos de Saúde de Juiz de Fora, Divinópolis e Ponte Nova, por sua vez, demandam mais tempo para análise (até 90 dias), discussão e apreciação de propostas, antes mesmo de sua efetivação. Não se pode, nesse caso, instigar a afirmativa de que os devidos Conselhos de Saúde operacionalizam suas atividades de forma ineficaz e ineficiente, uma vez que, segundo os dados dessa mesma pesquisa, o Conselho de Juiz de Fora, em relação aos demais, é o que mais realiza reuniões e sessões de participação abertas ao público externo. Nesse caso, constatou-se que dos conselhos pesquisados, o Conselho Municipal de Saúde de Juiz de Fora é o que mais realiza atendimento à população e o seu funcionamento coincide com os horários do comércio local.

Em relação à participação social externa, ou seja, aquela em que sujeitos do setor público, privado, terceiro setor e comunidade em geral podem opinar e participar das discussões e das deliberações das propostas apresentadas, fica evidente que em todos os sete Conselhos Gestores de Saúde Pública os indivíduos estão abertos a opinar e expor de forma propositiva suas ideias e opiniões a respeito das questões de saúde locais. Um fato notável é que embora a participação vocalizada seja permitida, o desenho institucional dos Conselhos de Saúde, a exemplo das críticas e fragilidades apontadas por Avritzer (2009), permite que apenas os membros do Conselho participem das votações que definem os rumos das ações debatidas e decisões tomadas. Isso pode ser evidenciado nessas explicações: "Participa, é aberto às reuniões, qualquer reunião, só não participa quando é extraordinária" (ENTREVISTA - PONTE NOVA, 2018), e em outros momentos: "Sim, e tem direito à voz, só não tem ao voto. É essencial, porém pelo descrédito e comodismo, acabam não fazendo ocupação nos espaços democráticos de direito" (ENTREVISTA- UBERLÂNDIA, 2018).

A comunicação e a forma de transmissão de informações foram destaques dessa pesquisa, uma vez que ficou evidente que a participação ativa e presente das pessoas e da comunidade local, para fiscalização e proposição de ideias para desenvolvimento de políticas públicas relacionadas à saúde, fosse relevante. As redes sociais nesse momento tiveram uma grande participação e um novo papel de disseminação de informações, para um novo papel institucional que esses Conselhos de Saúde têm para com seus representados. Ficou evidente na fala da conselheira em Uberlândia que embora reconheça limitações de eficácia de comunicação com a comunidade local, as redes sociais vêm como um meio gratuito de relacionamento e troca de informações: "Não temos financiamento para investir em divulgação das informações, mas fazemos de acordo com nossa possibilidade e redes sociais" (ENTREVISTA - UBERLÂNDIA, 2018). O mesmo ocorre no Conselho de Juiz de Fora. Neste, a comunicação se faz das seguintes formas: "Todos os meios, pessoais, telefonemas, por escrito. As pessoas têm o número do meu celular particular" (ENTREVISTA - JUIZ DE FORA, 2018).

Por fim, foi analisado se as quatro características principais do processo deliberativo estão em consonância com o desenho institucional atual dos sete Conselhos de Saúde investigados até aqui: Diamantina, Barbacena, Divinópolis, Juiz de Fora, Ponte Nova, Uberaba e Uberlândia. Essas características devem estar alinhadas com as definições de Brugué e Vallès (2005), sobre as bases da inclusividade, compreensibilidade e acessibilidade, economia moral de desacordo e a concretividade das decisões. Quanto ao 
aspecto de inclusividade, todos os Conselhos de Saúde analisados afirmaram que tanto os membros quanto a comunidade em geral têm a oportunidade de serem ouvidos e de ter suas propostas debatidas. Um trecho interessante explicita melhor esta constatação: "Isto é garantido no regimento interno do Conselho. Qualquer cidadão pode pedir pauta da reunião do Conselho e todos presentes à reunião tem direito à voz" (ENTREVISTA - UBERABA, 2018). Em relação à acessibilidade e compreensibilidade, da mesma forma, embora com características distintas, a comunidade em geral tem a oportunidade de expor suas ideias, estando, portanto, acessível às propostas que estão em debate e de forma que a população compreenda os caminhos que trouxeram as pautas até aqui, embora ainda haja cobrança por parte dos Conselhos para que a população esteja mais próxima e participativa: "A garantia existe, mas a participação é pouca, com frequência são reforçados os convites e necessidades de compromisso e assiduidade" (ENTREVISTA - DIAMANTINA, 2018).

O papel fiscalizador que o Conselho certamente se propõe a fazer é importante e demonstra seu poder de coercitividade, do ponto de vista positivo para que as decisões deliberadas pela população, de forma democrática, possam ser acatadas, e isso ficou demonstrado no caso particular do Conselho de Divinópolis:

A gestão pública dependendo do que o conselho faz lá, ela fica atenta porque ela não quer ser denunciada, e o conselho quando ele provoca algum questionamento, quando ele começa a investigar alguma coisa, ele "tá" investigando a gestão. Então em muitos casos a gente tem notícia de que as coisas andaram lá (ENTREVISTA - DIVINÓPOLIS, 2018).

Nesse sentido cabe ressaltar que o modelo ideal é aquele em que existe uma partilha de poder e responsabilidades, em que sociedade civil em geral, poder público, setor privado e terceiro setor possam opinar e participar ativamente de decisões importantes relacionadas à saúde pública, de forma a contribuir para a melhoria da saúde local ou regional, do aprimoramento da gestão pública e da primazia pela eficiência e efetividade das ações destinadas aos Conselhos de Saúde.

\section{CONSIDERAÇÕES FINAIS}

Este estudo teve como objetivo central analisar o processo decisório dos ConseIhos Gestores de Políticas Públicas de Saúde sob a ótica da Teoria Democrática Deliberativa. Dos 13 Conselhos de Saúde macrorregionais existentes em Minas Gerais, 5 não autorizaram acesso às informações e dados relacionados aos objetivos e problema do presente artigo, não corroborando para suprir lacunas em pesquisas realizadas sobre a mesma temática. Sete Conselhos de Saúde das principais macrorregionais em saúde de Minas Gerais, quais sejam, Barbacena, Diamantina, Divinópolis, Ponte Nova, Juiz de Fora, Uberaba e Uberlândia, aceitaram participar dessa nova fase da pesquisa sobre Processo Decisório na Gestão da Saúde Pública.

Constatou-se que existem preocupações primordiais dos representantes dos Conselhos de Saúde estudados, destacando-se a qualidade da saúde local/regional, o papel propositivo dos Conselhos e o aperfeiçoamento do papel de fiscalização e controle social. Os eleitos pelo voto têm peso considerável e representativo, e os membros presidentes de Divinópolis e Diamantina devem ter um papel ainda mais incisivo e fiscaliza- 
dor, uma vez que, diferentemente da prática deliberativa, tiveram indicações (por meio de votação livre) de outros conselheiros para chegarem ao posto da Presidência de seus respectivos conselhos representativos em âmbito local/regional. Reconheceu-se que os limites de atuação desses Conselhos (recurso financeiro escasso, quadro funcional reduzido, infraestrutura inadequada e falta de continuidade na formação e capacitação dos(as) conselheiros(as)) são barreiras para o desenvolvimento de novas perspectivas e aprimoramento de novos desenhos institucionais, e que apesar das limitações, as redes sociais tornaram-se importantes instrumentos de estreitamento de laços com a comunidade representada.

Ficou evidente que os membros tidos como mais "instruídos ou escolarizados" podem influenciar negativa e/ou positivamente outros membros dos Conselhos e seus representados, e que o questionamento acerca da atuação incipiente dos conselheiros, em alguns casos da falta de interesse da própria população, seja um empecilho para o avanço qualitativo desse desenho institucional voltado às práticas democráticas e de transparência. Sugere-se a realização de novas pesquisas, abordando outros desenhos institucionais ditos participativos e representativos, aplicados em democracias sólidas em outros países, atuando com base em correlação e causalidade, com objetivo de aprimoramento das atividades desenvolvidas pelos Conselhos Gestores de Saúde Pública.

Do ponto de vista de interesse por parte dos Conselhos de Saúde investigados, ações de engajamento participativo devem ser feitas com mais frequência, de forma que ocorra transmissão de competência para a população local/regional, e que o estreitamento da comunicação seja ainda maior, com novas políticas de cooperação, utilização de conselhos itinerantes, investimento em infraestrutura e a melhoria na qualidade da participação popular nas decisões deliberadas.

\section{REFERÊNCIAS}

AGUIAR, C. C. de; SILVA, E. A.; FERREIRA, M. A. M. Os efeitos das instituições participativas sobre a gestão pública municipal. In: ENCONTRO INTERNACIONAL SOBRE PARTICIPAÇÃO, DEMOCRACIA E POLÍTICAS PÚBLICAS, 2., 2015, Campinas. Anais [...]. Campinas: Unicamp, 2015. p. 1-22.

ARRETCHE, M. Políticas sociais no Brasil: descentralização em um Estado federativo. Revista Brasileira de Ciências Sociais, São Paulo, n. 40, v. 14, p. 111-141, 1999.

AVRITZER, L. Participatory institutions in democratic Brazil. Baltimore: Johns Hopkins University Press, 2009.

AVRITZER, L.; PEREIRA, M. D. Democracia, participação e instituições híbridas. Revista Teoria \& Sociedade, Belo Horizonte, n. especial, mar. 2005.

BARDIN, L. Análise de conteúdo. Lisboa: Edições 70, 2009.

BORBA, J. Participação política: uma revisão dos modelos de classificação. Revista Sociedade e Estado, Brasília, v. 27, n.2, p. 263-288, maio/ago. 2012.

BRASIL. Lei no 8142, de 28 de dezembro de 1990. Diário Oficial [da] República Federativa do Brasil, Poder Executivo, Brasília, DF, 31 dez. 1990. Seção 1, p. 25.694.

BRUGUÉ, Quim; VALLÈS, Josep Maria. New-style councils, new-style councillors: from local government to local governance. Governance, v. 18, n. 2, p. 197-226, 2005.

CARNEIRO, C. B. L. Conselhos de políticas públicas: desafios para sua institucionalização. Brasília: Enap, 2006.

COELHO, V. S. R. P. Conselhos de Saúde enquanto instituições políticas. São Paulo: 34 Letras, 2004.

CORREIA, M. V. C. Desafios para o controle social: subsídios para capacitação de conselheiros de saúde. Rio de Janeiro: Editora Fiocruz, 2005.

CÔRTES, S. M. V. Fóruns participativos e governança: uma sistematização das contribuições da literatura. Petrópolis: Vozes, 2005. p. 13-32. V. 1. 
DAGNINO, E. Sociedade civil e espaços públicos no Brasil. São Paulo: Paz e Terra, 2002.

DAHL, R. Democracy and its critics. New Haven: Yale University Press, 1989.

DALLARI, D. A. O que é participação política. São Paulo: Brasiliense; 1999.

DELUCHEY, J. F. A sociedade civil organizada e a administração governamental dos interesses: o exemplo dos conselhos paritários. Revista Estudos Políticos, Niterói, RJ, v. 2, n. 5, p. 77-101, 2012.

FENILI, R.; CORREA, C. E. G.; BARBOSA, L. Planejamento estratégico em saúde: ferramenta de gestão para o complexo de regulação em saúde. Gestão e Saúde, Brasília, v. 8, n. 1, p. 18-36, 2017.

FUNG, A. Empowered participation: reinvetingurban democracy. Princeton: UP, 2004.

GOHN, M. G. Conselho gestores e participação sociopolítica. São Paulo: Cortez, 2001.

LAKATOS, E. M.; MARCONI, M. A. Técnicas de pesquisa. 3. ed. São Paulo: Atlas, 1996.

MILANI, C. R. S. O princípio da participação social na gestão de políticas públicas locais: uma análise de experiências latino-americanas e europeias. Revista de Administração Pública, Rio de Janeiro, n. 42(3), p. 551-579, maio/jun. 2008.

O'DONNELL, G. Delegative democracy. Journal of democracy, Baltimore: The Johns Hopkins University Press, n. 1, 5. ed. p. 55-69, Jan. 1994.

OLIVEIRA, L. C.; PINHEIRO, R. A participação nos Conselhos de Saúde e sua interface com a cultura política. Revista Ciência e Saúde Coletiva, Rio de Janeiro, 2008. p. 1-10.

PATEMAN, C. Participation and democratic theory. 20. ed. New York: Cambridge, 1999.

SILVA, E. A. et al. Conselhos de Saúde: funcionamento, participação e compartilhamento da gestão. In: CONGRESO INTERNACIONAL DEL CLAD, 2014, Quito. Anais [...]. Quito, Ecuador, 2014.

SOUZA, C. Constitutional engineering in Brazil: the politic soffederalismand decentralization. London: Macmillan; New York: St. Martin's Press, 1997.

TATAGIBA, L. Os conselhos gestores e a democratização das políticas públicas no Brasil. São Paulo: Paz e Terra, 2002. p. 47-103.

VERGARA, S. C. Métodos de pesquisa em administração. Porto Alegre: AMGH, 2016.

YIN R. K. Case study research: design and methods. Thousand Oaks, CA: Sage, 2014. 